\title{
Issues and Challenges: Cloud Computing e-Government in Developing Countries
}

\author{
Naif Al Mudawi ${ }^{1}$, Natalia Beloff ${ }^{2}$, Martin White $^{3}$ \\ Dept. of Computer Science, University Najran ${ }^{1}$ \\ Dept.of Informatics, University of Sussex \\ Brighton, United Kingdom ${ }^{1,2,3}$
}

\begin{abstract}
Cloud computing has become essential for IT resources that can be delivered as a service over the Internet. Many e-government services that are used worldwide provide communities with relatively complex applications and services. Governments are still facing many challenges in their implementation of e-government services in general, including Saudi Arabia, such as poor IT infrastructure, lack of finance, and insufficient data security. This research paper investigates the challenges of e-government cloud service models in developing countries. This paper finds that governments in developing countries are influenced by how the top management deals with the attention to the adoption of cloud computing. Further, organisational readiness levels of technologies, such as IT infrastructure, internet availability and social trust of the adoption of new technology as cloud computing, still present limitations for e-government cloud services adoption. Based on the findings of the critical review, this paper identifies the issues and challenges affecting the adoption of cloud computing in egovernment such as IT infrastructure, internet availability, and trust adopted new technologies thereby highlighting benefits of cloud computing-based e-government services. Furthermore, we propose recommendations for developing IT systems focused on trust when adopting cloud computing in e-government services (CCEGov).
\end{abstract}

Keywords-Challenges; issue; privacy; security; social; egovernance services; citizen

\section{INTRODUCTION}

Recently, given the growing populations in developed countries, both economies and life expectancies have been improving. Further to this, governments should have improved online service systems [1]. This is described as the interchange by electronic means of data related to online services to make the delivery of e-government more efficient and effective [8]. Implementing online service systems, however, is a challenge at local, national and international levels, and this is especially so in developing countries.

Previous studies have provided some important obstacles in e-government, that impact the government in providing online services platform for citizens more effectively in the public sector [5]. e-Government systems in developing countries exhibit many direct and indirect variables influencing the adoption of new technologies, such as cloud computing, culture, social, facilitating conditions, lack of resources and limitation of experience [6]. Other research studies on e-government show consistent views that the adoption of the latest ideas, taken from a technology perspective, seeking to take advantage of potential implications around the development of e-government accessibility and services, are beneficial to citizens [7]. Thus, limitations in exploiting the benefits of ICT, by governments, could result in missing out on opportunities to deliver online services and affect the adoption of e-government by the public.

One of the other issues faced in developing countries is the lack of attention to the preservation of information on egovernment sites [12]. E-government sites should be constantly updated by procedural and policy changes; therefore, interactive features and mechanisms on the site must be tested on a regular basis, allowing the user to access offered services without any problems. This paper will contribute to understanding and identifying the challenges facing some government systems in developing countries, so ‘ the IS research can be able to identify any suitable solutions to these issues facing government systems.

This paper is organised as follows:

- A review of the concept of e-government.

- The paper then presents factors that influence adoption of e-government.

- We then propose that cloud computing has the potential to offer benefits to both implementation of efficient egovernment services and to users of those services.

- We then explore the challenges affecting the adoption of cloud computing in e-government services and how this research aims to overcome those challenges.

- And, finally, we draw some conclusions and suggest future work.

\section{BACKGROUND}

Electronic Government (e-Government) has been defined by many researchers. According to [9], e-government is defined as a method to provide government online services through the use of ICT to citizens, organisations and other stakeholders. E-government is seen as one of the best methods available, from a range of online and evolving public services over the Internet, and defines the use of the Internet to provide government information and services to citizens [10]. EGovernment essentially involves exploiting and promoting the Internet to provide information and services to citizens and organisations so as to increase their reliance on ICT. 
According to [11], the definition of e-Government is the relationship of communication between governments and clients (companies, other governments and citizens) through the Internet. In order to use the benefit of online services provided by governments, it is essential to reduce the gap between governments and stakeholders by improving communication and allowing optimal use of the online services.

\section{Challenges of E-Government}

E-Government plays a crucial role in processing information for the management of citizens and businesses by the government [12]. An e-government initiative may include a citizen-centric portal, online income tax, land and property system, e-learning, e-social services, government to employee portal and integrated financial management systems [13]. eGovernment has been associated with numerous challenges that make it difficult to be implemented in developing countries.

\section{A. ICT Infrastructure}

An inadequate ICT infrastructure is one of the major barriers against implementing e-government in developing countries. The government of a developing nation lacks the resources of establishing ICT infrastructure that is vital for the e-government [14]. The resources required for the implementation of e-government include digital technology, Internet network coverage and communication tools. The low availability of network coverage in developing countries restricts people from accessing e-government [19]. The Internet network is an essential factor for the utilisation of services provided on e-government websites and applications.

\section{B. Security and Privacy}

Privacy and security are critical elements of concern in the establishment of e-government in countries around the world [16]. However, these elements can be a barrier to the implementation of e-government in developing countries. The developed countries lack a proper strategy to assure their citizens that their information is protected from an unauthorised third party [25]. Subsequently, citizens in developing countries have little confidence in the privacy and security of their data in the e-government portal and website applications [18]. Therefore, the government should create policies that promote security and privacy in e-government, which will promote and instil privacy and safety confidence to the citizens.

\section{Senior Management}

Senior management of the governmental institutions has contributed to the difficulty of implementing e-government. Egovernment is not effective in developing countries because departmental managers are not committed to implementing its establishment in government [19]. Social culture hinders the management of ICT to advocate the utilisation of information and technology in the delivery of services in developing countries [20]. Organisational culture in developing countries is characterised by corruption and cronyism, which makes it challenging for government to implement management ICT in various departments.

\section{Social Influence}

Social factors have created challenges in the embracement of e-government in developing countries around the world. These factors include people's education and income and are a significant challenge to citizens adopting e-government in a growing country [13]. Most citizens lack education and skills in operating and accessing online services from the governmental portal websites [21]. Additionally, citizens are inflicted with low salary, which deters them from affording computer accessories and the Internet to access government portal websites.

\section{E. Lack of Awareness}

A lack of awareness of the existence of e-government in developing countries hampers the adoption of e-government technology in various aspects of government operation [22]. The majority of citizens tend to use manual means of accessing government services since they are unaware of egovernment [23]. Therefore, a lack of awareness deters the embracement of e-government in developing nations.

\section{Challenges of Adopting Cloud Computing IN E-GOVERNMENT}

Cloud computing has been utilised to improve communication and delivery of services in businesses and governments around the world [24]. Governments globally are moving with the advancement of technology, which has led them to invest in cloud computing in e-government systems. However, the adoption of cloud computing in e-government has faced numerous challenges, which makes it a debatable issue for its establishment in a nation.

\section{A. Privacy Risk}

Privacy is one of the risks facing cloud computing in egovernment. Cloud computing does not have the aspects of storing and processing of information at the local organisation, whereby it is conducted by a third party [25]. The involvement of a third party in storing information exposes cloud computing information to unauthorised and unwanted users being able to access citizens' confidentiality [26]. Additionally, the third party has a tendency to store cloud computing information in various areas, which makes people lose confidence in its ability to maintain privacy [19]. Therefore, the vulnerability of cloud computing compromises the rights of people to maintain the privacy of their sensitive information utilised in e-government systems. The integration of cloud computing with e-government systems translates to abundant sensitive information is contained within the technology [3]. That is, stored information tends to be delicate and sensitive, making it unsuitable to fall into the hands of a malicious party.

\section{B. Technology Readiness}

Cloud computing is readily available to be integrated into e-government [15]. However, governments must lease cloud services from a cloud computing provider as a third party [27]. The failure of a provider to form a consensus with a government in adopting the technology or use in egovernment services, means that a government may not access 
and utilise cloud computing services if the cloud provider declines to offer the services of their technology.

\section{Reliability}

A government would be concerned about a reliable egovernment-based cloud technology to invest in the various services-oriented organisations [17]. The cloud relies on a high quality successful system in government operations relying on the e-government portal and applications [28]. A system failure based on cloud services results in the stoppage of numerous services that are crucial in the running of government operations in both public and private sectors [22]. Therefore, it may lead to massive loss of financial transactions that are generated through operations that occur on egovernment websites and applications [22]. Additionally, system failure inflicts distrust in the users of cloud computing integrated into e-government.

\section{Security Concerns}

Security is a fundamental issue in requiring the establishment of cloud-based e-government in countries around the world [4]. Security deficiencies in cloud computing technology exposes e-government to confidentiality and integrity risks of sensitive information; inadequate security in cloud-based e-government inflicts distrust by users of egovernment [23]. Therefore, the government should consider selecting a cloud computing provider who has established high-security measures that protect operations integrated within the technology.

\section{E. Trust in the Internet}

Governments have minimal trust in the storage of confidential and classified information on the Internet. Government tends to take control of everything concerning the affairs of their citizens through directly protecting sensitive information [14]. However, the provision of cloud services by a third party impedes them from control of their sensitive information [21]. Additionally, government does not have the power and mandate to control activities that occur in the cloud [2]. Therefore, most governments around the world tend to have little trust in the storage of data using Internet mechanisms.

\section{BENEFITS OF AdOPTING ClOUd COMPUTING IN E-GOVERNMENT}

Cloud computing has recently been merged with egovernment system of countries around the world [19]. This innovative technology has a considerable number of benefits that make it a vital asset to the provision of information and services to citizens and business [29]. The benefits generated from adopting cloud computing include flexibility, efficiency, availability, reliability, system integration and numerous others

\section{A. Scalability}

Cloud computing has high scalability aspects that make it easily integrated into the e-government systems. The technology is regarded to be scalable so it can be configured with IT resources such as servers and hard drives [30]. Therefore, the government can integrate cloud-based egovernment with various essential operations that occur in the country. The scalability of cloud computing makes it suitable for it to be integrated into e-government systems of developing countries [31]. Cloud computing technology is suitable to be adopted in the dynamics that are occurring in the growth of businesses in developing countries.

\section{B. Flexibility}

The adoption of cloud computing in e-government makes it flexible in the government's system. Therefore, cloud-based e-government can be utilised at different levels and sectors in government [22]. Cloud computing has different models that enable ICT experts to configure it according to business expectations and organisations [32]. Businesses in the private sector may employ a cloud hybrid computing model, which has a significant benefit to an organisation as businesses gain the leverage that is experienced by public and private models.

\section{Cost Reduction}

The establishment of e-government requires a high financial investment of the system in the country. It involves the purchase of ICT equipment and software essential for the proper delivery of services to citizens and businesses [13]. Additionally, a government will need to hire ICT professionals who will handle and maintain -government system [21]. The incorporation of cloud technology will provide a positive opportunity incurred in the establishment of the e-government system.

\section{Pay as you use}

Cloud computing technology advocates the use of pay as you go pricing, which enables a government to save a massive amount of money [18]. Additionally, the investment of cloud computing enables e-government managers to eliminate the cost of power, storage facilities and space of operation [33]. Therefore, cloud computing is a cost-saving technology that minimises investment incurred in e-government.

\section{E. Systems Integration}

The integration of cloud computing with e-government eases the management of the system. Cloud computing eradicates the need for intensive management in an egovernment portal and applications [25]. Cloud computing has the aspect of self-service demand, stimulated through the presence of a secure interface that allows authorising individuals to access e-government information and services [19]. A government is aided by cloud providers in the management of cloud security in e-government. The service provider has a mass of resources, which are employed to enhance security in the e-government systems.

\section{DISCUSSION}

Government agencies have been looking forward to the benefits of adopting cloud computing in the organisation's system. This paper highlights that the organisational readiness levels in terms of IT infrastructures and senior management supports and influences the adoption of cloud computing. Accordingly, when encouraging government agency adoption of cloud computing, senior management should highlight how the organisation's system can benefit from the positive outcomes of the adoption of cloud computing. In addition, senior management may need to pay attention to 
organisational readiness levels of technologies, such as Internet availability, and how the sociocultural influences affect the adoption of cloud computing.

Adoption of cloud computing has many issues that might hinder implementation. These challenges can be categorised as technological, organisational and environmental. Technological and organisational challenges can be seen as lapses in IT governance in developing countries, which must be managed by the organisation's senior management. IT management concerns the security regulations provided by the cloud computing provider, which means they have to pay attention to adopting new technologies. Accordingly, decisions must be made to ensure effective use of the adoption of cloud computing in the e-government system. Finally, the significant influences in the adoption of cloud computing in egovernments concern security and privacy, which needs to improve the process to mitigate against high risks. This paper recommends that cloud computing is one of the best solutions to overcome the lack of IT infrastructure from keeping up with the requirements of high quality of e-government. Additionally, the incorporation of cloud technology will provide a positive opportunity to reduce costs in the development of the e-government system.

\section{CONCLUSION}

Cloud computing has been widely adopted in many online systems. The nature of e-government varies from one country to another and is associated with a number of challenges facing organisations in increasing adoption. This paper is aimed at exploring the concept of e-government. In addition, it highlights the benefits of e-government adoption in developing countries such as cost reduction and pay as you use. In addition, this paper has identified the issues and challenges affecting the adoption of cloud computing in egovernment in developing countries like security concerns, lack of awareness and, poor ICT infrastructure. Thus, this paper discussed some recommendations that could lead to increasing adoption of cloud computing e-government systems to overcome the obstacles in their limitations to deliver online services. Finally, Future work will conduct an empirical study to investigate the factors influencing the decision of top management to adopt cloud computing in e-government systems which interpret survey results to help and offer more explanations for these results.

\section{REFERENCES}

[1] M. Meftah, B. Gharleghi, and B. Samadi, "Adoption of E-government among Bahraini citizens," Asian Soc. Sci., vol. 11, no. 4, pp. 141-149, 2015.

[2] S. C. J. Palvia and S. S. Sharma, "E-Government and e-governance: definitions/domain framework and status around the world," Found. eGovernment, pp. 1-12, 2007.

[3] E. A. Abu-Shanab, "E-government familiarity influence on Jordanians' perceptions," Telemat. Informatics, vol. 34, no. 1, pp. 103-113, 2017.

[4] S. Alateyah, R. M. Crowder, and G. B. Wills, "Identified Factors Affecting the Citizen's Intention to Adopt E-government in Saudi Arabia," Int. J. ..., vol. 7, no. 8, pp. 601-606, 2013.

[5] A. A. Oni, S. Oni, V. Mbarika, and C. K. Ayo, "Empirical study of user acceptance of online political participation: Integrating Civic Voluntarism Model and Theory of Reasoned Action," Gov. Inf. Q., vol. 34, no. 2, pp. 317-328, 2017.
[6] M. S. Wong and S. Jackson, "User satisfaction evaluation of Malaysian e-government education services," 2017 Int. Conf. Eng. Technol. Innov. Eng. Technol. Innov. Manag. Beyond 2020 New Challenges, New Approaches, ICE/ITMC 2017 - Proc., vol. 2018-Janua, pp. 531-537, 2018.

[7] L. Alzahrani, W. Al-Karaghouli, and V. Weerakkody, "Analysing the critical factors influencing trust in e-government adoption from citizens' perspective: A systematic review and a conceptual framework," Int. Bus. Rev., vol. 26, no. 1, pp. 164-175, 2017.

[8] J. C. Bertot, P. T. Jaeger, and J. M. Grimes, "Using ICTs to create a culture of transparency: E-government and social media as openness and anti-corruption tools for societies," Gov. Inf. Q., vol. 27, no. 3, pp. 264$271,2010$.

[9] S. Kim, "Individual-level factors and organizational performance in government organizations," J. Public Adm. Res. Theory, vol. 15, no. 2, pp. 245-261, 2005.

[10] V. K. Prasad, M. Shah, N. Patel, and M. Bhavsar, "Inspection of Trust Based Cloud Using Security and Capacity Management at an IaaS Level," Procedia Comput. Sci., vol. 132, no. Iccids, pp. 1280-1289, 2018.

[11] D. Danish, "The Failure of E-Government in Developing Countries: A Literature Review," Electron. J. Inf. Syst. Dev. Ctries., vol. 26, no. 7, pp. $1-10,2006$.

[12] Q. Cao and X. Niu, "Integrating context-awareness and UTAUT to explain Alipay user adoption," Int. J. Ind. Ergon., vol. 69, no. September 2018, pp. 9-13, 2019.

[13] A. Alkhwaldi, M. Kamala, and R. Qahwaji, "From e-govemment to cloud-government: Challenges of Jordanian citizens' acceptance for public services," 2017 12th Int. Conf. Internet Technol. Secur. Trans. ICITST 2017, pp. 298-304, 2018.

[14] P. Joshi and S. Islam, "E-Government Maturity Model for Sustainable E-Government Services from the Perspective of Developing Countries," Sustainability, vol. 10, no. 6, p. 1882, 2018.

[15] F. Mohammed, O. Ibrahim, and N. Ithnin, Factors influencing cloud computing adoption for e-government implementation in developing countries: Instrument development, vol. 18, no. 3. 2016.

[16] S. M. Wu and Y. C. Wu, "Development of Smart Cities in Taiwan From the Perspective of Cloud Computing Security," ISPRS - Int. Arch. Photogramm. Remote Sens. Spat. Inf. Sci., vol. XLII-4/W16, no. October, pp. 667-670, 2019.

[17] L. Waller and A. Genius, "Barriers to transforming government in Jamaica: Challenges to implementing initiatives to enhance the efficiency, effectiveness and service delivery of government through ICTs (e-Government)," Transform. Gov. People, Process Policy, vol. 9, no. 4, pp. 480-497, 2015.

[18] H. Choi, M. J. Park, and J. J. Rho, "Two-dimensional approach to governmental excellence for human development in developing countries: Combining policies and institutions with e-government," Gov. Inf. Q., vol. 34, no. 2, pp. 340-353, 2017.

[19] J. Wu, F. Ding, M. Xu, Z. Mo, and A. Jin, "Investigating the Determinants of Decision-Making on Adoption of Public Cloud Computing in E-government," J. Glob. Inf. Manag., vol. 24, no. 3, pp. 71-89, 2016.

[20] F. Zhao, K. N. Shen, and A. Collier, "Effects of national culture on egovernment diffusion - A global study of 55 countries," Inf. Manag., vol. 51, no. 8, pp. 1005-1016, 2014.

[21] C. Mutimukwe, E. Kolkowska, and Å. Gr, "Electronic Government," vol. 10428, pp. 324-335, 2017.

[22] U. Sivarajah, A. Omar, H. Lee, R. Hackney, Z. Irani, and R. ElHaddadeh, "Cloud Based e-Government Services: A Proposal to Evaluate User Satisfaction Americas Conference on Information Systems Cloud Based e-Government Services: A Proposal to Evaluate User Satisfaction,” Twenty-third Am. Conf. Inf. Syst., no. 1, 2017.

[23] P. Bakunzibake, Å. Grönlund, and G. O. Klein, "E-government implementation in developing countries: enterprise content management in Rwanda," Electron. Gov. Electron. Particip. Jt. Proc. Ongoing Res. Proj. IFIP WG 8.5 EGOV ePart 2016, vol. 23, no. February, pp. 251259, 2016. 
[24] N. Wang, Y. Xue, H. Liang, Z. Wang, and S. Ge, "The dual roles of the government in cloud computing assimilation: an empirical study in China," Inf. Technol. People, vol. 32, no. 1, pp. 147-170, 2019.

[25] I. Arpaci, "A hybrid modeling approach for predicting the educational use of mobile cloud computing services in higher education," Comput. Human Behav., vol. 90, no. January 2018, pp. 181-187, 2019.

[26] C. fei Chen, X. Xu, and L. Arpan, "Between the technology acceptance model and sustainable energy technology acceptance model: Investigating smart meter acceptance in the United States," Energy Res. Soc. Sci., vol. 25, pp. 93-104, 2017.

[27] Y. Liang, G. Qi, K. Wei, and J. Chen, "Exploring the determinant and influence mechanism of e-Government cloud adoption in government agencies in China," Gov. Inf. Q., vol. 34, no. 3, pp. 481-495, 2017.

[28] P. K. Senyo, J. Effah, and E. Addae, "Preliminary insight into cloud computing adoption in a developing country," J. Enterp. Inf. Manag., vol. 29, no. 4, pp. 505-524, 2016.
[29] Y. Li, L. Zhu, and W. Tu, "Research on e-government data management in cloud computing environment," Proc. - 2019 Int. Conf. Smart Grid Electr. Autom. ICSGEA 2019, pp. 289-292, 2019.

[30] I. Khan, H. ur Rehman, M. H. F. Al-khatib, Z. Anwar, and M. Alam, "A thin client friendly trusted execution framework for infrastructure-as-aservice clouds," Futur. Gener. Comput. Syst., vol. 89, pp. 239-248, 2018.

[31] Q. Alajmi, R. A. Arshah, A. Kamaludin, A. S. Sadiq, and M. A. AlSharafi, "A conceptual model of e-learning based on cloud computing adoption in higher education institutions," 2017 Int. Conf. Electr. Comput. Technol. Appl. ICECTA 2017, vol. 2018-Janua, pp. 1-6, 2018.

[32] T. Almarabeh, Y. K. Majdalawi, and H. Mohammad, "Cloud Computing of E-Government," Commun. Netw., vol. 08, no. 01, pp. 1-8, 2016.

[33] P. F. Hsu, S. Ray, and Y. Y. Li-Hsieh, "Examining cloud computing adoption intention, pricing mechanism, and deployment model," Int. J. Inf. Manage., vol. 34, no. 4, pp. 474-488, 2014. 